Open Access

\title{
Prerequisites for artificial intelligence in further education: identification of drivers, barriers, and business models of educational technology companies
}

André Renz ${ }^{*}$ and Romy Hilbig

* Correspondence: a.renz@udk berlin.de

University of the Arts Berlin / Weizenbaum Institute for the Networked Society, Hardenbergstraße 32, 10623 Berlin, Germany

\begin{abstract}
The ongoing datafication of our social reality has resulted in the emergence of new data-based business models. This development is also reflected in the education market. An increasing number of educational technology (EdTech) companies are entering the traditional education market with data-based teaching and learning solutions, and they are permanently transforming the market. However, despite the current market dynamics, there are hardly any business models that implement the possibilities of Learning Analytics (LA) and Artificial Intelligence (AI) to create adaptive teaching and learning paths. This paper focuses on EdTech companies and the drivers and barriers that currently affect data-based teaching and learning paths. The results show that LA especially are integrated into the current business models of EdTech companies on three levels, which are as follows: basic Learning Analytics, Learning Analytics and algorithmic or human-based recommendations, and Learning Analytics and adaptive teaching and learning (Al based). The discourse analysis reveals a diametrical relationship between the traditional educational ideal and the futuristic idea of education and knowledge transfer. While the desire for flexibility and individualization drives the debate on Al-based learning systems, a lack of data sovereignty, uncertainty and a lack of understanding of data are holding back the development and implementation of appropriate solutions at the same time.
\end{abstract}

Keywords: Learning analytics, Algorithms-based learning, Artificial intelligence, Further education, Higher education, Business models, Educational technology

\section{Introduction}

Based on current technological developments and already existing applications in the field of digital education, such as mobile apps, learning management solutions, and plagiarism software, Popenici and Kerr (2017) raise the critical question of who will set the educational agenda in the future, namely, corporate ventures or educational institutions. Large digital and technology-driven ventures, such as Netflix, Samsung, Google, Microsoft, and Facebook-also called techlords-are trying to develop new data-based learning programs that enable new didactic tools in public institutions

(C) The Author(s). 2020, corrected publication 2021. Open Access This article is licensed under a Creative Commons Attribution 4.0 International License, which permits use, sharing, adaptation, distribution and reproduction in any medium or format, as long as you give appropriate credit to the original author(s) and the source, provide a link to the Creative Commons licence, and indicate if changes were made. The images or other third party material in this article are included in the article's Creative Commons licence, unless indicated otherwise in a credit line to the material. If material is not included in the article's Creative Commons licence and your intended use is not permitted by statutory regulation or exceeds the permitted use, you will need to obtain permission directly from the copyright holder. To view a copy of this licence, visit http://creativecommons.org/licenses/by/4.0/. 
through these business-driven companies (Rittelmeyer, 2017). For example, the Netflix group developed the learning program DreamBoxLearning for mathematics in the US market, which enables personalized learning based on Artificial Intelligence (AI) technologies with an adaptive intelligent learning system. ${ }^{1}$ That these techlords are investing intensively in the development of AI-based teaching and learning solutions inevitably raises the question of whether educational institutions are ready to implement such data-driven technology in their teaching and learning programs (Ifenthaler \& Yau, 2019). Answering these and similar questions is challenging due to the unstructured market, lack of evidence, and topic-specific complexity (Luckin et al., 2016). Moreover, although the market for educational technology (EdTech) is predicted to grow worldwide to $\$ 8$ trillion in 2020, the market is growing much more slowly than other markets are with the dynamics of digital transformation. A major reason for this is the number and complexity of decision makers-educators, teachers, traditional textbook publishers, and politicians, to name a few-who are involved in the market (EdTechXGlobal Report, 2016; Startup Genome, 2018). In addition, the definition of EdTech has changed over the years. While 10 years ago, the mere provision of classrooms with computers was referred to as EdTech, today, EdTech refers to many startups and other organizations working to transform education and quality through the use of technology (Startup Genome, 2019). In the context of this work, we follow the definition of EdTech as "the digitization of educational services and business models" by software companies that provides technology solutions for schools, colleges, or businesses (Startup Genome, 2018). As a result, the educational landscape is increasingly influenced by business-driven companies, such as the big techlords, SMEs or startups. Thus, technological developments like AI, Machine Learning (ML), and Learning Analytics (LA) inevitably find their way into teaching and learning methods and require the development of digital, data-based business models.

In Germany, the higher education system, also known as the tertiary sector, is subdivided into universities, universities of applied sciences, vocational schools, and further education (Deutscher Bildungsserver, 2019; KMK, 2017). ${ }^{2}$ We focus on the area of further education, which is becoming increasingly relevant in the course of digital transformation and lifelong learning, as job profiles and requirements will change fundamentally and permanently. To better define the still young and fast-growing EdTech market, we focus our empirical studies on the German-speaking area (Germany, Austria, Switzerland), the so-called DACH region. A characteristic element of this specific further education market is the dual education model, which combines theoretical and practical learning in an effective and successful way (Abdelkafi, Hilbig, \& Laudien, 2018). Traditional vocational training providers are facing the make-or-buy decision of whether to buy the EdTech solutions or develop them independently. At the same time, the competitive pressure on vocational training providers is growing as EdTech companies not only offer software solutions but also become training service providers. A closer look at the literature shows that there are hardly any studies from the perspective of EdTech companies (Hilbig, Renz, \& Schildhauer, 2019). We try to fill

\footnotetext{
${ }^{1}$ http://www.dreambox.com, 30.07.2019.

${ }^{2}$ Although most of the current literature refers to higher education in universities, in the context of this paper we equate higher and further education. This reflective approach is intended to compensate the currently still modest research efforts in the area of further education.
} 
this gap. For this purpose, the paper identifies digital, data-driven business models of EdTech companies operating in the field of further education. The purpose is to understand their business models and the extent to which they are already implementing AI in their value propositions to develop teaching and learning methods through digital technologies. Furthermore, using the same empirical example, we investigate the drivers and barriers by implementing LA and AI.

We focus on the two following research questions:

(1) What is the current role of LA- and AI-based learning solutions in the business models of EdTech companies regarding the field of further education?

(2) What are the drivers and barriers of LA- and AI-based learning solutions in the EdTech sector regarding further education?

The paper is structured as follows: First, we define the terms AI, AI in Education (AIED), and LA and distinguish them from the further terms Educational Data Mining $(E D M)$ and ML. The definition is intended to show more clearly the current use of AI and LA in the field of education. The two-stage qualitative research design is described in section "Qualitative Research Design". The fourth section first presents the status quo of LA- and AI-based solutions in further education. Based on these results, we use a discursive approach to identify drivers and barriers of AI-based solutions in further education. Section "Conclusion and further research" closes this paper with a short summary of the research results and the setting of recommendations for subsequent studies.

\section{Artificial intelligence in further education}

The current discussion about AIED is characterized by two essential aspects-the distinction between LA, EDM, ML, and AI and the challenges of pedagogically meaningful implementation. In particular, there is often no clear distinction between LA and AIED. A major reason for this is the missing evidence for the application and effect of the terms in education (Ifenthaler \& Yau, 2019; Renz, Krishnaraja, \& Gronau, 2020; Sclater, Peasgood, \& Mullan, 2016). The aspect of a meaningful implementation is important because the barriers are still high when it comes to using data-based EdTech solutions concretely and meaningfully in the existing learning and teaching process (Alexander et al., 2019; Zawacki-Richter et al., 2019). To eliminate the issue of distinction in the present paper and improve the understanding of the empirical study in sections "Qualitative Research Design" and "Research results", the first step is defining AI and AIED and roughly outlining their relationships with LA, ML, and EDM.

\section{Definition of artificial intelligence in education}

One of the first and still most influential definitions of AI was established by McCarthy: "The study [of AI] is to proceed on the basis of the conjecture that every aspect of learning or any other feature of intelligence can in principle be so precisely described that a machine can be made to simulate it" (Popenici \& Kerr, 2017; Russell \& Norvig, 2010). In the past decades, the understanding of the term AI has become more 
differentiated, depending on the discipline (e.g., mathematics, chemistry, linguistics, and teaching and learning in education). Motivated to understand the profound association between education and AI in terms of knowledge presentation, reasoning, and learning, the first research projects in the field of AIED were already initiated in the early 1970s (Self, 2016). Since then, international research interest has steadily increased. Today, numerous conferences, committees, and social and political events are dedicated to the complex spectrum of AIED themes. One of the most common definitions of AIED was formulated by Popenici and Kerr (2017). These authors define AIED as "computing systems that are able to engage in human-line processes such as learning, adapting, synthesizing, self-correction and the use of data for complex processing tasks." According to Luckin et al. (2016), AIED per se can be defined as an interdisciplinary research area, whereby the interdisciplinary character is located on several levels. Integrating methods and results from the learning sciences (psychology, neuroscience, education, linguistics, anthropology, and sociology), AIED aims to develop integrative, adaptive, personal, flexible, and effective learning environments that complement and optimize traditional education and training. Recent publications on AIED focus on questions like what it truly implies, what we can expect from the use of AIED, and where the current limits for its use are (Holmes, Bialik, \& Fadel, 2019). ${ }^{3}$

Weller (2018) outlines important technological developments that have shaped the education sector over the past 20 years. Starting with wikis in the late 1990s, the development led to Massive Open Online Courses (MOOCs) in 2012 and large platforms, such as edX, that have arisen in just the past few years (Rothe, Täuscher, \& Basole, 2018; Weller, 2018). Today, innovative teaching and learning methods can be combined with digital technology, such as virtual and augmented reality; cloud computing; and digital media, such as images, video, or audio (Kalyani \& Rajasekaran, 2018; Trifilova, Bessant, \& Alexander, 2016). Luckin et al. (2016) summarize the current use of AIED software applications into the three following categories: a) intelligent support for collaborative learning, b) personal tutors, and c) intelligent virtual reality. AIED can support collaborative learning by organizing the online collaboration of a learning group, representing the teacher, or establishing teams and building a personal connection with each student (Istrate, 2019). In addition, the possible applications relate to the personalization of individual lessons, so that decisions can be made regarding the learning path of an individual student and the content. Intelligent virtual reality can be used to create authentic virtual realities and playful learning environments or to have learners supervised by virtual tutors (Jonassen et al., 1995; Perez et al., 2017).

AIED changes the education system sustainably on all levels. Thus, AI opens new possibilities not only for learning and teaching but also the administration and management of educational institutions. Although the relevance of AIED is continuously increasing, Renz et al. (2020) note that there are only a few examples in the current discourse that have already implemented AIED successfully and sustainably in higher education. We briefly discuss some AIED lighthouse projects in section "Research results". Arroway, Morgan, O'Keefe, and Yanosky (2016) comment that LA and the use of AIbased solutions is currently more a matter of interest than priority in most institutions.

${ }^{3}$ In the following we will use the terms AI and AIED synonymously. 
Other studies confirm this observation (e.g., Colvin et al., 2015; Newland, Martin, \& Ringan, 2015). Tsai and Gasevic (2017) identify the lack of institutional strategies that also consider the cultural, economic, political, and technical context of the individual institution as a major obstacle to establishing LA in institutions.

\section{Relationships between learning analytics, data mining, and machine learning and artificial intelligence}

While the datafication of our social reality is increasingly growing, and hence, more processes of our daily life are being transformed into objectifying data structures, it is often unclear when we can say that AIED, ML, LA, or EDM is present. The most striking link is evident between the terms ML and AI. Popenici and Kerr (2017) note that "'machine learning' is a promising field of artificial intelligence" in higher education. In this regard, Lorenz and Saslow (2019) state, "AI traditionally refers to the scientific pursuit of teaching machines to think like humans, or more simply, the automation of cognitive processes." Consequently, they consider ML as a subdiscipline of AI, consisting of data and learning algorithms that are fed into a software program able to create patterns, summaries, or conclusions about certain phenomena (e.g., of teaching and learning). The foundation for this is a corresponding hardware component that drives everything (Lorenz \& Saslow, 2019; Popenici \& Kerr, 2017). In addition, ML is only possible if big datasets are available. This can be mapped for almost all sectors of digitization, making Big Data a sufficient condition for ML and AI applications in the education sector. Gartner (2012) defines Big Data as "high-volume, high-velocity and high-variety information assets that demand cost-effective, innovative forms of information processing for enhanced insight and decision making." In this commonly cited definition, the attribute "big" concentrates on the three dimensions of volume, velocity, and variety, which are extended by "value" and "veracity" to 5Vs-considering the entrepreneurial value of data and the assurance of data quality (Bitkom, 2015; Eckert, Henckel, \& Hoepner, 2014). These characteristics of Big Data constitute the basic understanding in our empirical analyses.

While ML as a component of AI does not need to be further delimited in the context of our work, the terms LA and EDM need to be considered in a more differentiated way. In principle, AIED, LA, and EDM are the research communities that encompass the concept of technology-enhanced learning and use of available digital data to improve the quality of higher education (Labarthe, Luengo, \& Bouchet, 2018; Renz et al., 2020). Renz et al. (2020) illustrate the relationships among these terms in the context of education (see Fig. 1).

An analysis by Labarthe et al. (2018) shows that all three communities focus on "students," "learning," and "uses," with the EDM and LA communities focusing on data, while AIED does not. Viberg et al. (2018) add academic analytics to LA and EDM. According to their understanding, academic analytics and EDM are closely related; while academic analytics focuses more on supporting the higher education institution, EDM concentrates on providing automated decisions and predictions using ML algorithms. Furthermore, LA concentrates on visualizing the data to provide a deeper insight into the student's learning experience and helps further optimize the learning environment (e.g., developing automated recommendations for the teaching and learning process). 


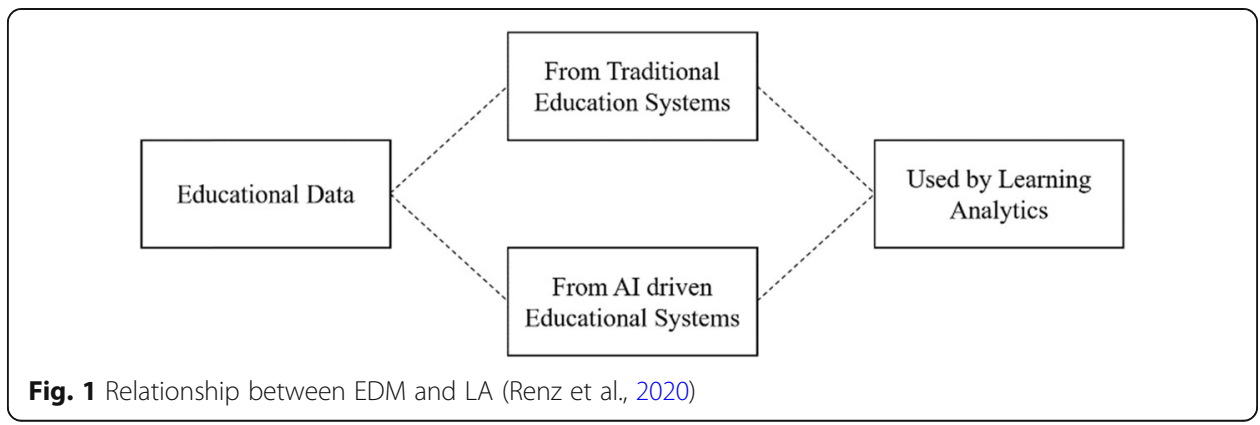

The focus of AIED is providing intelligent agents and tutors through AI-supported learning platforms (Alexander et al., 2019; Labarthe et al., 2018; Renz et al., 2020).

While EDM is not highly relevant for the explanations below, we understand LA and $\mathrm{AI}$ as consecutive elements. LA builds the groundwork by collecting data and information about the teaching and learning behavior in a digital environment, and it is used to better understand and shape the learning and teaching processes. At the next level, AI models human-like processes based on LA (Fahimirad \& Kotamjani, 2018; Lorenz \& Saslow, 2019). As a consequence, a mapping of the current landscape of contemporary AI research in higher education is also always inevitably linked to a mapping of LA. Viberg et al. (2018) give a comprehensive overview of the current status quo of LA in higher education while analyzing 252 papers on LA with a special focus on how LA research has been employed across different higher educational disciplines, settings, and institutional types. They point out that the definitions of LA vary, but the common understanding of LA refers to it as "the measurement, collection, analysis and reporting of data about learners and their contexts, for purposes of understanding and optimizing learning and the environment in which it occurs" (Long \& Siemens, 2011). Furthermore, the analysis of Viberg et al. (2018) shows that research in LA is still in its infancy. The analysis of the 252 papers identified that only $9 \%$ of research can prove an influence of LA to improve learning support and teaching in higher education at this stage.

Having classified the essential terms related to the topic, the next section is devoted to the empirical analysis. The subject of the analysis will be EdTech companies, which are mainly located in the German-speaking economic region. Digital technologies make it possible to collect data on teaching and learning processes in the field of further education. The potential of AI-based learning and teaching, which requires the analysis of large amounts of data, promotes the development of new, refined smart learning tools, algorithm software, and predictive modeling (Mayer-Schonberger \& Cukier, 2014; Williamson, 2018). The EdTech sector creates such new, innovative, and smarter teaching and learning models that improve the performance of individuals or whole organizations and lead to new business models in all areas of education (i.e., school, university, vocational training, and further education) (Startup Genome, 2018). Digital, data-driven business models are developed by techlords, small and medium-sized enterprise (SMEs), and startups, which are transforming the further education system. 


\section{Qualitative research design}

The research design is based on two main steps. First, we provide a qualitative content analysis from interviews with 25 EdTech companies in the field of further education. The purpose is to understand their business models and the extent to which they are implementing LA and AI in their value propositions to develop teaching and learning methods through digital technologies. The business model concept is becoming increasingly important in science and practice (Baden-Fuller \& Mangematin, 2015; Ritter \& Lettl, 2017; Zott, Amit, \& Massa, 2011). While most research focuses on the user side of EdTech, we deliberately change the perspective and look at EdTech companies. The analysis of the business models of EdTech companies is still a young field of research, and it is increasingly becoming a focus of research, particularly due to digitization (Abdelkafi et al., 2018; Hilbig, 2019). With our research, we contribute an important impulse for a better understanding of market dynamics in the EdTech sector and mapping the current status of the implementation and application of LA- and AIbased teaching and learning systems.

With the help of digital platforms and learning systems, new, innovative teaching and learning concepts are emerging. In combination with digital tools, these promote datadriven business model innovations (Daniel, Vázquez Cano, \& Gisbert, 2015; Prifti et al., 2017). Following causality, data are also increasingly becoming a key resource in the field of education (Hartmann et al., 2016; Hilbig, Estiwah, \& Hecht, 2018; Schüritz, Seebacher, \& Dorner, 2017). The basis for the analysis of the EdTech business models is the definition by Teece (2010) as "design or architecture of the value creation, delivery, and capture mechanism." In addition to identifying business models, we focus on the drivers and barriers that influence LA- and AI-based teaching and learning systems in the German-speaking economic area. The semi-structured interview guideline focuses on the business model regarding the three main dimensions of value proposition, value delivery, and value capture (Teece, 2010). The main categories are shown in Table 1.

The interviews were conducted between October 2018 and June 2019. The average time for an interview was 1:01:05 h. In total, representatives of 12 EdTech startups, 11 EdTech SMEs, one large company, and one university project were interviewed. The interviews were mainly conducted with the chief executive officers (CEOs) of the companies. The interviews were randomly transcribed, with additional information on websites, press articles, social media channels, or free software accesses from the first part of the analysis. The desk research was added to the dataset for each EdTech company. Following Mayring (2010), the individual categories were based on the theoretical foundations (deductive) of the Business Model Framework and derived from the

Table 1 Main categories of the interview

(a) Establishment/development of the EdTech company

(b) Advantages and disadvantages of digitalization in general

(c) Value proposition: focus on digital teaching and learning approaches; establishment of digital or data competences; usage of digital technology, e.g., LA and/or Al; target market; unique selling point

(d) Value delivery: focus on key resources in general and data as specific key resources; aspects and importance of data security, data protection and privacy, data ethics; key processes of the company in general and in regard to data, such as data analytics

(e) Business model type: data-driven, data-enhanced, low data, platform 
existing text material in terms of the research questions (deductive). For coding, we used an inductive-deductive approach. The interview coding was carried out by two researchers, and the results were reviewed by the third researcher. The results of the coding process are presented in Fig. 2 and described in section "Research results".

In a second step, the interviews were complemented via a discursive analysis, whereby the discourse was positioned on a scientific level. Online and mass media reports were excluded. We followed the conceptual understanding of Foucault, where the object of investigation only gains significance through discourse (Freikamp, 2008; Jäger, 2015). The discourse can be understood as an attempt to stabilize ascriptions of meaning and orders of meaning, at least temporarily, and thus, to institutionalize a collectively binding knowledge order in a social ensemble. However, discourse analysis per se does not follow a specific method; rather, it is a research perspective on a concrete object of research (Keller, 2011). The chosen approach was qualified for the present analysis, since both the qualitative interviews and the discourse follow a conversational-analytical perspective, and thus, support each other in their content. In addition, the multidisciplinary character of the study required a combined analysis as the empirical analysis alone could hardly identify all drivers and barriers in the context of implementing LA and AI in higher education. The chosen approach should enable us to obtain as comprehensive as possible an overall picture of the atmosphere in relation to LA and AI in higher education. Through the discursive approach, we were able to develop a basic understanding of the dynamics of the EdTech market and algorithm-based AI systems. The data were then coded for qualitative content analysis (Mayring, 2010).

Following the coding process, we discussed and validated the evaluations again using a design thinking in science approach workshop with four different researchers to validate the empirical data, literature review, and discourse analysis. All four researchers had different research backgrounds (as behavioral scientist, humanities scholar,

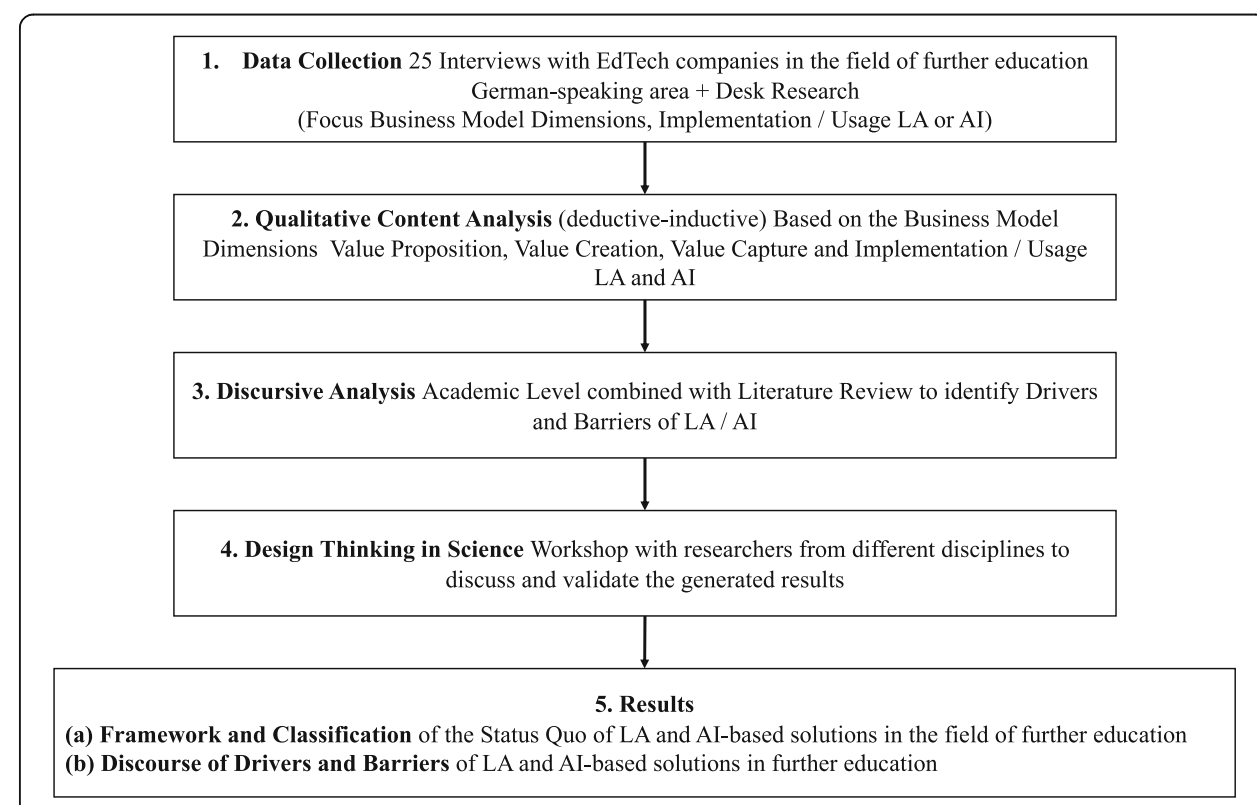

Fig. 2 Research design 
industrial engineer, business economist), so that the generated results and thoughts were reviewed from different perspectives. In the next step, the adjusted results from the workshops were discussed and expanded by researchers in the field of pedagogy and informatics. By using different data sources and different researchers, the dataset was triangulated to increase the reliability and interdisciplinarity of the study (Denzin, 1970; Yin, 2014). Figure 2 summarizes the research design and steps of the current study.

\section{Research results}

\section{Status quo of LA and Al-based solutions in further education}

The business models are examined based on Teece's (2010) main dimensions of value proposition, value delivery, and value capture, but the main research focus is understanding how the 25 EdTech companies generate, analyze, visualize, or distribute data and to what extent they use LA- or AI-based solutions. All 25 EdTech companies offer digital services in the field of further education, with a wide range of educational services. The spectrum of services ranges from the development and hosting of learning software to the creation of didactic concepts and implementation of digital training programs. The overview that follows summarizes the value proposition of the 25 EdTech companies (Fig. 3).

Eight EdTech companies offer software as a service (SaaS) in the field of further education, (i.e., e-learning, micro-learning, virtual and augmented reality developments, or game-based learning solutions). The SaaS solutions are developed in house by the EdTech companies in cooperation with the customers themselves. Didactic as a service (DIaaS) prepares the contents of digital teaching and learning elements for customers, such as companies or universities (Prifti et al., 2017). The EdTech providers become the creators and authors of the digital content. With the dynamic development of the EdTech market, new professional fields are emerging for educators, who now act as authors and design digital teaching and learning units for schools, universities, and further education. In our sample, there are nine providers offering a combination of SaaS developments and DIaaS. One company offers DIaaS combined with their own online trainings. There are three EdTech companies that provide SaaS solutions and online

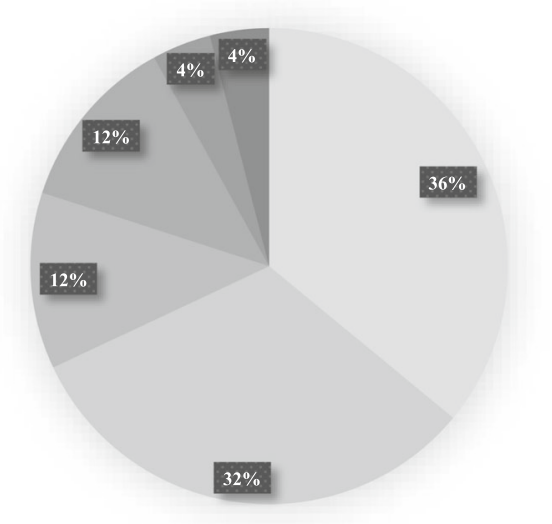

Software as a Service + Didactic as a Service

$\square$ Software as a Service

- Online Training

- Software as a Service + Online Training

- Educational Consulting

- Didactic as a Service + Online Training

Fig. 3 Value proposition of the 25 EdTech companies 
trainings, while there are three providers that only provide training, representing variations of e-learning, blended-learning, and offline training. One EdTech company in the sample operates in the field of educational consulting services to develop and implement further education in companies.

The interviewed EdTech companies are united in that they offer digital educational services allowing teaching and learning behavior to be measured. Our data can confirm the theoretical explanations in section "Artificial Intelligence in Further Education". Measuring, collecting, analyzing, and interpreting data is an essential prerequisite for developing AI-based teaching and learning solutions. Figure 4 represents an adopted and extended form of the different data paths of EdTech companies in the field of further education. In addition, it shows the current status of the usage and implementation of LA of the EdTech companies. To the best of our knowledge, this is the first attempt to map the existing LA levels on the EdTech market. Although studies by Zawacki-Richter et al. (2019) and Viberg et al. (2018) have extensively analyzed existing research on LA and AIED, there is no clear differentiation regarding the degree to which LA and AI are implemented in teaching and learning processes.

Figure 4 outlines two ways in which EdTech companies use digital data in their business models. The first path characterizes low data business models, that is, where the data generated by digital teaching and learning solutions are transmitted directly to the customer. The EdTech company is not able to access the data; therefore, it cannot use them for the development of its value propositions. The EdTech company fulfills only the function of data routing, and it cannot implement LA. The generated data of the teaching and learning behavior are stored on the server of the customer. In our research, eight EdTech companies reported being on this path. The collection and analysis of the generated learning and teaching data are not part of the business model or offered services of these eight EdTech providers. The second path in Fig. 4 is

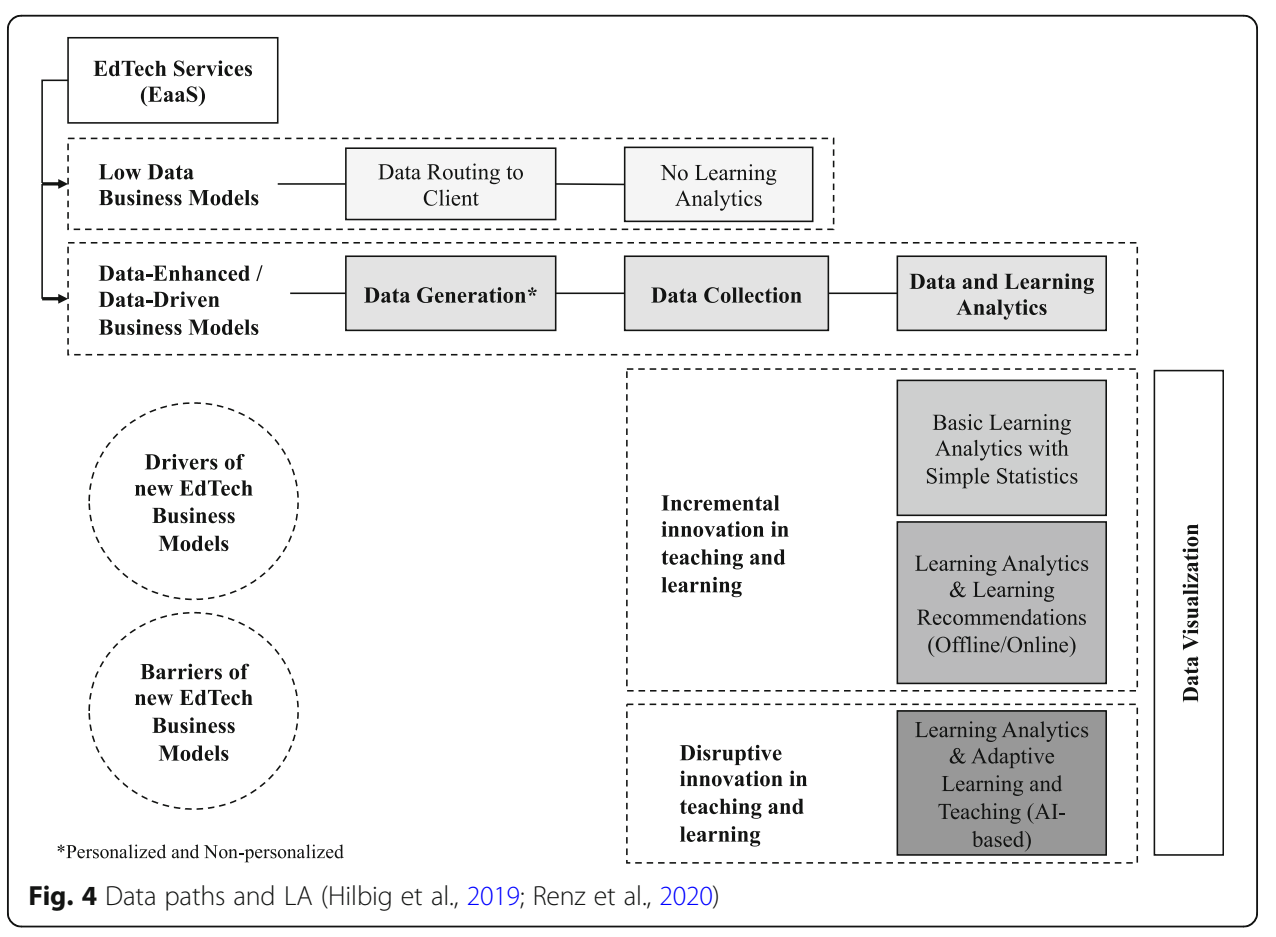


determined by the EdTech companies having access to the generated data of the users' teaching and learning behavior (data generation). The generated data are collected by the EdTech companies; this can be split into personalized user data and nonpersonalized user data, depending on the regulations of the client and/or country. Based on our empirical data and a study by Picciano (2014), we identified three different levels of so-called LA in the field of further education:

Figure 5 shows that, with increasing data collection and implementation of data in the optimization of teaching and learning solutions, the level of LA increases. In our sample, eight companies are implementing basic LA as part of their digital services. Two are using Google Analytics, for example, as a tool to generate these basic statistics of the learning and teaching behavior. The collection and analysis of user data, such as frequency analysis or mean value (simple statistics), represent the click behavior, usage behavior, or media choice of the user, processed as visual graphs, tables, or bar charts. This can be compared to the beginnings of e-commerce, where click and purchase behaviors were presented in simple statistical analyses in the early 2000s. At the second level, we can observe that basic LA is already being used in combination with customized learning recommendations based on the click, usage, learning, or teaching behavior or the media choice. Interestingly, we could identify two different types of recommendations, namely, algorithm-based and human-based recommendations. The digital user of the educational online service receives algorithm-based recommendations on what to learn next and in which order. The software of the EdTech company analyses the user data by creating patterns and classification through algorithms and combining them with the digital learning content to improve, customize and innovate the teaching and learning process based on the user's individual needs. Three companies of the sample already offer these levels of LA. Regarding our analysis, basic LA is needed to implement a self-learning software that enables digital educational services to establish an individual and adaptive learning system based on the teaching and learning behavior of

\begin{tabular}{|c|c|c|}
\hline Basic LA & $\begin{array}{l}\text { LA + algorithm-based } \\
\text { and/or human-based } \\
\text { recommendations }\end{array}$ & $\begin{array}{c}\mathrm{LA}+\text { adaptive teaching and } \\
\text { learning }(\mathrm{AI})\end{array}$ \\
\hline $\begin{array}{l}\text { LA is used to measure the } \\
\text { participants' online } \\
\text { performance. Measurements } \\
\text { include how much time } \\
\text { learners spend in a course, } \\
\text { the number and type of } \\
\text { classroom interactions, } \\
\text { assessments, content } \\
\text { (videos, articles or } \\
\text { simulations), and } \\
\text { collaborative activities } \\
\text { (discussion groups, blogs, } \\
\text { wikis). } \\
8 \text { EdTech companies }\end{array}$ & $\begin{array}{l}\text { LA is used to improve } \\
\text { academic advice related to } \\
\text { teaching and learning. To } \\
\text { achieve this, teaching } \\
\text { lessons are linked to other } \\
\text { data in the student } \\
\text { information system (higher } \\
\text { education entrance } \\
\text { qualification, age, major } \\
\text { subject). The LA software } \\
\text { can monitor performance } \\
\text { across the entire } \\
\text { organizational hierarchy. } \\
4 \text { EdTech companies }\end{array}$ & $\begin{array}{l}\text { By using LA, longitudinal } \\
\text { analyses can be created that } \\
\text { can be used to derive } \\
\text { predictive behavioral } \\
\text { studies and patterns. }\end{array}$ \\
\hline
\end{tabular}

Fig. 5 Levels of LA in the field of further education (Picciano, 2014) 
the user through AI. The digital system/software optimizes and customizes the teaching and learning content without human intervention. It will also revolutionize the teaching process, as the content of lessons will be created automatically using algorithms. This step will involve the disruptive innovation of teaching and learning through digitalization and a future scenario. Only two providers mentioned projects where they tried to individualize and optimize the teaching and learning process in a virtual space by means of AI.

Only one of 25 EdTech companies (Case 25) offered all three levels of LA as a service according to the needs of the client. For the basic LA, they created dashboards for their customers in which the frequencies of online behavior are visualized. In a second step, these dashboards can be combined with algorithmic or human-based recommendations. The development of the third level is currently being extended and trained with neural networks. This LA as a service has become part of the value proposition of Case 25, but this EdTech company argues that companies need to set up learning ecosystems in the course of training so that employees can learn individually "just in time" and "just in case."

In summary, 14 companies in the sample already use one of these three levels of LA as a service in their business models, while 11 suppliers indicated that LA is currently not part of their business model. The empirical study shows that the area of LA, as well as that of AI-based learning, is still in its infancy in the field of further education in the German-speaking countries. Regarding the business model perspective, the classification of Hilbig et al. (2018) was used to identify that the sample represents two pure data-driven business models, 22 data-enhanced business models, and one low data business model (Interview Case 15). Therefore, we see the future of innovative teaching and learning methods in the implementation of LA combined with adaptive learning and self-learning systems (AI based).

\section{Drivers and barriers of LA- and Al-based solutions in further education LA- and Al-based solutions in higher education}

LA- and AI-based teaching and learning solutions have the potential to change education drastically. Following Buschbacher (2019), such new technologies are always caught between enthusiasm and rejection. Some see them as long sought-after solutions to existing and future challenges, whereas others view them as a further step toward incapacitation. Both perceptions are equally exaggerated and harmful, as they block the view of the benefits and side effects of the solutions. In the second section, we already pointed out that there are currently only a few LA- and AI-based teaching and learning solutions on the market. The application is often only theoretically explored but not implemented in practice. Below, we first summarize the best-known cases that have successfully implemented such solutions in the education sector. Subsequently, drivers and barriers are presented, derived from our empirical analysis in combination with discourse analysis.

As described in the previous section, different levels of LA can be distinguished depending on data collection and usage. To develop intelligent, adaptive, and personalized learning systems, large amounts of data on learners' behavior and habits need to be collected and analyzed (Holmes et al. 2019). Although AI technology has been the focus 
of scientific interest for more than 60 years, practical applications in education have only recently been advanced (Russell \& Norvig, 2010). Techlords like Amazon and Google have invested in promising AI systems that will have a lasting impact and change teaching and learning behavior. For example, data-based business models like Carnegie Learning, Knewton, and Bettermarks can be seen on the emerging market (Renz et al., 2020). These companies develop AI-based solutions for education and further education based on teaching and learning data. For example, Knewton collects user data and establishes links between the learning behaviors of individual learners. Based on this, learning types or success prognoses can be derived. In the next step, complex algorithms based on this database define individual learning packages where the content and speed are continuously adapted. Following this, complex algorithms define individual learning packages on this data basis, with ongoing adaptation of the contents and speed (Renz et al., 2020). ${ }^{4}$ Software solutions like Knewton seem to eliminate a previously unsolvable tension-access to education for all with individually designed curricula (Dräger \& Müller-Eiselt, 2017). Currently, universities increasingly rely on such algorithm-based solutions to support learning success, curricula, and the study process per se. One of these successful projects is based at Deakin University in Australia. Deakin University integrates IBM's supercomputer, Watson, which provides 365 days of feedback to students. ${ }^{5}$ Since 2011, Austin Peay State University uses Degree Compass, which generates course recommendations for students according to the same logic employed by Amazon and Netflix. Among other things, the Compass predicts the probability of passing a course. ${ }^{6}$ Another example of algorithm-based solutions is the eAdvisor used by Arizona State University. The personalized eAdvisor guides students through their studies, and all user data/behavior is recorded. ${ }^{7}$

The examples listed here are already being successfully implemented, but at the same time, they represent only flagship areas of AIED. Renz et al. (2020) have investigated AIED in a research project and hardly found any teaching and learning solutions that were truly AI-based. Beyond that, numerous questions remain unanswered: What are the long-term consequences of the almost unlimited data measurement of our learning behavior? What are the drivers and barriers? Is the European EdTech market ready for such solutions? With the help of a theoretical discursive approach, drivers and barriers in the debate about AI-based learning systems in higher education, especially further education, can be roughly outlined. As mentioned above, further education will become increasingly important in the course of digital transformation and lifelong learning as job profiles and requirements change fundamentally. Following Arroway et al. (2016), institutions of higher and further education now have a great chance to proactively establish themselves as owners and drivers in the future of LA- and AI-based learning solutions. The theoretical discourse primarily includes scientific reflections and should be validated by the findings of our qualitative study.

\footnotetext{
${ }^{4}$ https://www.knewton.com

${ }^{5}$ https://www.deakin.edu.au/about-deakin/media-releases/articles/ibm-watson-helps-deakin-drive-the-digitalfrontier

${ }^{6}$ https://www.apsu.edu/academics/what-sets-apsu-apart/

${ }^{7}$ https://eadvisor.asu.edu
} 


\section{Drivers and barriers of Al-based solutions in higher education}

Based on the 25 interviews and a discursive analysis, we identify drivers and barriers for AI-based teaching and learning solutions, which are summarized below (Fig. 6).

While most drivers and barriers can be clearly identified, there are four elementscultural change, sustainability, individualization, and human-digital-interaction-that have been classified as both driving and inhibiting AIED. The interviews showed that cultural change especially follows a diametric relationship. The change is taking place in the tension between a traditional understanding of education and a futuristic idea of education and knowledge transfer. Learning behavior and the requirements for learning methods are constantly changing. In this context, it is evident that an increased circulation of knowledge can be considered by using digital approaches due to the permanent availability of knowledge. Following Loop (2016), individuals-and especially employees-turn to search engines for information and knowledge; often, when knowledge is needed, they can do so without leaving their workflow. This shows a drastic change in the training and learning culture. While unorganized, often context- and problemdependent real-time training is increasingly gaining importance, the relevance of corporate training is clearly decreasing. Direct access to experts, knowledge and learning freely available online intensifies this trend.

\section{Drivers}

Maseleno et al. (2018) accentuate the potentials that LA can assume in the context of individualized learning. Here, the learner is assigned a much more active role than in the current, traditional sense of further education. Among other things, learners are encouraged to participate effectively in promoting a solid learning environment, mindfully consider its individual adaptation needs, and identify and apply learning methods that work best for them. Avella et al., (2016) illustrate how the use of Big Data is beneficial for a wide range of higher education contexts. Advantages are shown in the use of academic analytics to improve learning. By analyzing Big Data, researchers can identify useful information that educational institutions, students, faculty, and researchers can use in various ways. These include targeted course offerings, curriculum development, student learning outcomes and behaviors, individualized learning, improved teacher

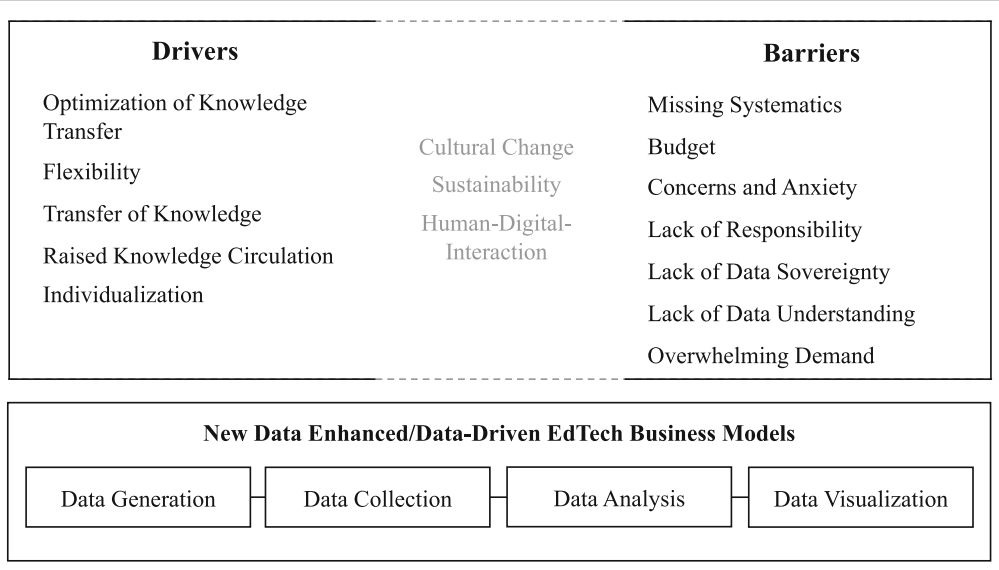

Fig. 6 Drivers and barriers for the development/implementation of Al-based solutions 
performance, post-training employment opportunities, and improved educational research. In this regard, Manyika et al. (2011) comment: "In a big data world, a competitor that fails to sufficiently develop its capabilities will be left behind [...] Early movers that secure access to the data necessary to create value are likely to reap the most benefit." Authors like Macfadyen, Dawson, Pardo, and Gaševic (2014) or Slade and Prinsloo (2013) follow this view. Thus, Macfadyen et al. (2014) note that education can no longer avoid the use of LA, while Slade and Prinsloo (2013) maintain, "Ignoring information that might actively help to pursue an institution's goals seems shortsighted to the extreme." Huda et al., (2017) argue that individualized learning increases students' motivation and engagement. This makes learning more sustainable, as students are actively involved in shaping their learning journeys. The evaluation of the interviews with EdTech companies supports all these claims on a theoretical level. Both scientific findings and EdTech providers are pushing for greater support for data-based and datadriven systems in education.

\section{Barriers}

Although research in LA and its close field of AI has demonstrated high potential for understanding and optimizing learning behavior and processes (Baker \& Siemens, 2014), few studies deal with the acceptance or barriers of LA and AI in the specific field of further education. Tsai and Gasevic (2017) identify six general challenges-shortages of leadership, equal engagement, pedagogy-based approaches, sufficient training, studies empirically validating the influence by LA, and LA-specific policies-related to the strategic planning and implementation of LA in institutions. Avella et al. (2016) identify data tracking, data collection, data analysis, optimization of the learning environment, and new technologies as the main challenges in the discourse on the use of LA in higher education. Ferguson and Clow (2017) ask whether LA improves learning in practice. With their contribution, they try to relate the current research results in LA to the following four issues: whether LA practices support learning, support teaching, are widely used, and are ethically used. The results show only vague evidence, suggesting that LA is not immune to pressure in other areas. In addition, the authors note that LA is a diverse, multidisciplinary field of research, making it much more challenging to obtain generalizable, valid, and reliable evidence. Our findings also suggest that a lack of evidence and a lack of systematic approaches represent barriers to the development of LA- and AI-based solutions in the market.

Several studies criticize the promise that the use of AI-based solutions in higher education can design individualized learning. With reference to section "Artificial Intelligence in Further Education" of this paper, we think that AI-based solutions in continuing education follow cumulative learning behavior monitoring of other students rather than a holistic individual learning creation. Software solutions, such as Knewton, can establish links between the learning behavior of individual users, deriving forecasts about learning success or classifications of learning types. However, only recommendation algorithms are ultimately generated (Dräger \& Müller-Eiselt, 2017). Although there are currently no AI-based learning systems available on the observed market, another more fundamental problem emerged in the interviews: Neither data collection nor evaluation has yet been used for individualization. In this context, authors 
like Bond et al., (2018) and Collins and Halverson (2009) have already stated that technology as the sole driver of innovation in education is not enough. Rather, innovations in curricula, structures, organizations and companies are needed to make the digital revolution in education a reality. In our data, the skepticism and concerns of companies, particularly the relevant works councils, are cited as the main barriers. Besides, EdTech companies can only state a low level of data understanding or sovereignty in dealing with the corresponding data of the decisive instances in the respective companies. This finding coincides with the results of Seyda, Meinhard, and Placke (2018), who showed that companies only use Big Data analyses to a limited extent. Out of the 25 EdTech companies surveyed, 14 offer some type of LA. As a final consequence, EdTech companies only have limited access to data for the further development of their services.

The conflicting relationship between the desire for individualization of the teaching and learning journey and the unwillingness of customers to analyze data can be explained primarily by the lack of data sovereignty. The interviews also express a lack of technical understanding, fear of control and general ignorance of technical potentials as further significant barriers to the development of digital teaching and learning formats. In addition, users are often overwhelmed with the technical possibilities and adopt a passive or negative attitude toward digital solutions. One interviewee commented, "To be honest, we don't work with Learning Analytics because we have experienced that the data basis is missing and that the companies are so far away in terms of maturity and the HR [human resources] department is still partly working in the Stone Age. I say that quite clearly. We are simply, in reality [...] still so far away from these analytics, in the area of human resources, from learning that there is simply no market for them at the moment" (Interview Case 18). Analogously, another interviewee said: "I was with my colleague a few days ago [...] at a common known customer, and he said: 'Can't I have the tool cheaper if I skip the analysis?' [...] Well, that's exactly what they said. Did they recognize it or guess it right? The companies are not ready yet-which is a disadvantage for the companies and for us" (Interview Case 9).

Although the data quality, and thus, the reliability of the recommendation algorithms generated in this way increase with the increasing digitalization of education, we follow Dräger and Müller-Eiselt's (2017) argument that the complexity of the individual educational pathways cannot be fully represented by algorithmic solutions. In this vein, Gasevic et al., (2016) observe that instructional conditions, study subjects, and participants influence the success of studies using online learning systems and algorithmbased predictions.

The discourse also focuses on ethical aspects associated with the use of LA/AI in higher education. Ferguson (2012) advocates for the development and application of ethical guidelines that regulate the use of Big Data generated by systems based on LA. Throughout the discourse, it becomes increasingly apparent how significant the uncertainty related to data collection, analysis, and transmission is. This uncertainty is often reflected in long-term perspectives-that is, what consequences will participants have in their future professional life due to the data collected today? Following Prinsloo, Slade, and Galpin's (2012) argumentation, the identity of participants is to be viewed as a combination of permanent and dynamic attributes. Slade and Prinsloo (2013) extend this idea and describe LA as a snapshot of a learner at a certain point in time and in a 
certain context. Therefore, the data collected through LA should have an agreed lifetime and expiration date and mechanisms for students to request the deletion of the data according to agreed criteria. In this context, Buckingham Shum and Ferguson (2012) suggest that the aim of LA should always be to improve the learning process rather than reflect the performance of the past. Correspondingly, Buschbacher (2019) emphasizes that making mistakes is an essential part of the learning process and requires a secure room that is not being monitored.

The discursive excursus illustrates that the theoretical debate on questions of the permanence of the recorded learning data, further processing, and the self-autonomy of data suppliers has already experienced a certain dynamic. However, practice cannot answer these questions. The interviews with EdTech companies have shown that neither the companies nor the institutions using digital educational services are willing and/or able to make meaningful use of potential learning data. The dilemma of LA and AI in higher education is reflected precisely here. A decisive, albeit intuitive, cause of this dilemma is identified by Buschbacher (2019): "Human discourse cannot be replaced by AI." As one of our 25 respondents said, "[Our method] follows an approach that says that people learn from people. The more digital the world becomes, the more humane our content must be" (Interview Case 10). Concerning the second level of LA in the area of further education, we found that one of the 25 respondents consciously integrated human interaction in the business model (Interview Case 19). The integration of human interaction in the digital learning processes should be emphasized here once again as a consensual understanding across all the interviews.

\section{Conclusion and further research}

By changing the perspective from a user focus to a provider focus, we have identified that differences between technical possibilities through digitalization and actual application remain distinct. The education sector continues to face various barriers in the development and implementation of LA- and AI-based solutions. We have identified challenges not only at the level of application but also at the theoretical level. For example, the distinction of terms between LA and AI is often vague. The results of our study can support previous studies by Arroway et al. (2016), Colvin et al. (2015), and Newland et al. (2015). Arroway et al. (2016) comment that LA and the use of AI-based solutions are more of interest than a priority in most institutions. According to Dräger and Müller-Eiselt (2017), the education sector intrinsically lacks acceptance for the implementation of AI-based solutions. This lack of acceptance is complex and evident at various levels. The results of our 25 interviews support this observation. The current development dynamics in the market are clearly slowed down by the restrained demand. Tsai and Gasevic (2017) identify the lack of institutional strategies as a major obstacle for a successful implementation of LA and AIED in institutions. In our observation, the lack of strategic orientation results from a lack of understanding of data and insufficient data sovereignty. This situation is supported by institutional obstacles such as works councils, which often have a negative attitude toward the datafication of employees' training behavior. These observations are not surprising, as the contrast between what is digitally feasible and our analog reality is still very large.

The discrepancy is particularly evident in the diametric relationship of cultural change, which takes place within the tension between a traditional understanding of 
education and a futuristic idea of education and knowledge transfer. Accordingly, the discourse typically takes place on a theoretical level. Furthermore, a lack of evidence remains for the successful and effective implementation of LA and AIED (Ifenthaler \& Yau, 2019; Renz et al., 2020; Sclater et al., 2016). With reference to Ferguson and Clow (2017), the evidence of LA can currently only be vaguely proved; in addition, the discourse operates mainly in the area of university education. An expansion to the field of further education is crucial. As mentioned earlier, the relevance of further education will increase in the context of the new dynamics of knowledge transfer caused by digital transformation. Corresponding studies of the continuing-training sector are therefore necessary.

Many questions remain unanswered, both at the theoretical and practical level. For example, at which point does it make sense to implement LA and AI in a digitally supported learning system? How can the data thus generated be interpreted and used effectively? And how can the autonomy of the individuals whose learning behavior is measured be guaranteed in relation to their own data? In particular, data-protection concerns arising from the handling of users' private information and ethical challenges in the use of data need to be further pursued (Li, 2007). Even though ethical, private and social concerns about LA have been criticized, very little evidence is to be found when we examine papers on ethical implications (Ferguson \& Clow, 2017). In particular, ethical aspects have shown increasing importance in discussions of the use of AI in education. We believe that digital sovereignty in all areas of life can only be guaranteed if self-determination over one's own data is also secured. Our analysis of the EdTech companies and our qualitative interviews show that personalization will radically change the existing education system. Such a paradigm shift, however, also requires a general rethinking and a cultural change.

Despite the current challenges, the education market appears to be slowly opening up to the development and implementation of LA and AIED. Based on our qualitative investigations, we have defined three levels of integrating LA within an EdTech business model: Basic LA; LA + algorithm- or human-based recommendation; and LA + adaptive teaching and learning (AI-based). These levels have been implemented by 14 companies in our sample, but mainly through Basic LA or LA + algorithm- or humanbased recommendations. The proclaimed disruptive innovation through LA + adaptive teaching and learning (AI-based) seems more of a future scenario in the field of further education than a possible reality by now. Digitization can only offer sustainable added value for the education and training sector when opportunity and reality are entered into the dialogue and are used to develop a common understanding of future steps. In addition to legal restrictions, it is above all the individuals themselves who strive for self-determined and human interaction in their own teaching and learning journeys. With this finding, our study again distinguishes itself and supports previous research by Huda et al. (2017) and Seyda et al. (2018). Not the EdTech companies, but the customers/users currently set the dynamics on LA and AI within the EdTech sector. Whether this trend will change cannot be deduced from our first study. This situation will certainly require further in-depth studies.

Also, our results have shown that the current business models of EdTech companies are far less data driven than is intuitively assumed. Interestingly, because providers assign data little to no relevance as a means of payment, we can suppose that a larger gap 
and increased potential exist in the processes of innovation in further education in the context of digital transformation, especially in comparison with other industries. Both research questions were able to be answered by our qualitative research design.

One of the study's limitations is that only 25 EdTech companies were interviewed and analyzed in detail. In order to provide further directions and recommendations, more EdTech companies must be considered. This research field is still in its infancy, however, and further studies on the implementation of LA and AI in the field of further education are necessary to understand how digitalization changes our educational system through the emergence of new businesses. To summarize, this study has provided initial insights into how LA is the prerequisite for AI in the field of further education.

\section{Acknowledgments}

Not applicable.

\section{Authors' contributions}

The empirical data was generated by André Renz (AR) and Romy Hilbig (RH) to equal parts. Section three of the paper was also written by both to equal parts, as well as the introduction (section one) and the conclusion (section five). The definition part was mainly written by $\mathrm{RH}$ and complimented by AR. The interviews were conducted and analyzed by AR and Rh as well. While RH was focusing on the business model in section "Research results" of the paper, AR was analyzing the drivers and barriers of the algorithm-/AI based solutions. The author(s) read and approved the final manuscript.

\section{Funding}

Our work has been funded by the Federal Ministry of Education and Research of Germany (BMBF) under grant no. 16DII111 (Deutsches Internet-Institut). This research project was funded by the German Federal Ministry of Education and Research (Funding Number: 16DII115). The authors are responsible for the content of this publication.

\section{Availability of data and materials}

The datasets used and analyzed during the current study are available from the corresponding author on reasonable request. This article contains on elements and 19 qualitative interviews that have been previously considered for the conference publication Data Analytics - The Future of Innovative Teaching and Learning at ISPIM Florence (1619.06.2019). For this article, the data have been extended by the authors through additional interviews, discourse analysis, a design thinking in science approach, and different theoretical foundations in the field of further education and artificial intelligence. In addition, the dataset will be used for another article by Renz, Krishnaraja, and Gronau, titled "Demystification of Artificial Intelligence in Education-How Much Al is Really in the Educational Technology?" in the International Journal of Learning Analytics and Artificial Intelligence for Education respectively will refer to the conference contribution for this.

\section{Competing interests}

The authors declare that they have no competing interests.

Received: 7 August 2019 Accepted: 17 March 2020

Published online: 06 April 2020

\section{References}

Abdelkafi, N., Hilbig, R., \& Laudien, S. M. (2018). Business models of entrepreneurial universities in the area of vocational education-an exploratory analysis. International Journal of Technology Management, 77, 86-108.

Alexander, B., Ashford-Rowe, K., Barajas-Murphy, N., Dobbin, G., Knott, J., McCormack, M., ... Weber, N. (2019). EDUCAUSE horizon report: 2019 higher education edition.

Arroway, P., Morgan, G., O'Keefe, M., \& Yanosky, R. (2016). Learning Analytics in Higher Education. Research report. Louisville: ECAR https://ibrary.educause.edu/ /media/files/library/2016/2/ers1504la. Accessed 31 Jul 2019.

Avella, J. T., Kebritchi, M., Nunn, S. G., \& Kanai, T. (2016). Learning analytics: Methods, benefits, and challenges in higher education: A systematic literature review. Online Learning, 20(2), 13-29.

Baden-Fuller, C., \& Mangematin, V. (2015). Business models and modelling business models. Advances in Strategic Management, 33, xi-xxii.

Baker, L., \& Siemens, G. (2014). Educational data mining and learning analytics. In R. K. Sawyer (Ed.), Cambridge handbook of the learning science, (pp. 253-272). Cambridge: University Press.

Bitkom. (2015). Big data und Geschäftsmodell-Innovationen in der Praxis: 40+ Beispiele, Berlin. https://www.bitkom.org/ Bitkom/Publikationen/Big-Data-und-Geschaeftsmodell-Innovationen-in-der-Praxis-40-Beispiele.html. Accessed 10 Oct 2019.

Bond, M., Marin, V. I., Dolche, C., Bedenlier, S., \& Zawacki-Richter, O. (2018). Digital transformation in German higher education: Student and teacher perceptions and usage of digital media. International Journal of Educational Technology in Higher Education, 48, 1-20.

Buckingham Shum, S., \& Ferguson, R. (2012). Social learning analytics. Educational Technology \& Science, 15(3), 3-26.

Buschbacher, J. (2019). EdTech - Zukunft der Bildung: Wie die Bildung der Zukunft durch neue Technologien unterstützt und verändert wird und welche Kompetenzen Bildungsexperten unbedingt aufbauen sollten. Ludwigsburg: Eigenverlag. 
Collins, A., \& Halverson, R. (2009). Rethinking education in the age of technology: The digital revolution and the schools. New York: Teachers College Press.

Colvin, C., Rogers, T., Wade, A., Dawson, S., Gasevic, D., Shum, S. B., ... Fisher, J. (2015). Student retention and learning analytics: A snapshot of Australian practices and a framework of advancement. The Australian Government Office for Learning and Teaching http://www.olt.gov.au/project-student-retention-and-learning-analytics-snapshot-current-australian-practicesand-framework. Accessed 31 Jul 2019.

Daniel, J., Vázquez Cano, E., \& Gisbert, M. (2015). The future of MOOCs: Adaptive learning or business model? RUSC Universities and Knowledge Society Journal, 12(1), 64-73.

Denzin, N. K. (1970). The research act: A theoretical introduction to sociological methods. New York: Routledge.

Deutscher Bildungserver. (2019). Gesamtüberblick zum deutschen Bildungssystem, URL: https://www.bildungsserver.de/ Gesamtueberblick-zum-deutschen-Bildungssystem-506-de.html. Accessed 01 Aug 2019.

Dräger, J., \& Müller-Eiselt, R. (2017). Die digitale Bildungsrevolution: Der radikale Wandel des Lernens und wie wir ihn gestalten können. München: DVA Verlag.

Eckert, K.P., Henckel, L., \& Hoepner, P. (2014). Big data - ungehobene Schätze oder digitaler Albtraum 19. Berlin: Fraunhofer Fokus.

EdTechXGlobal (2016). EdTechXGlobal report 2016—Global EdTech industry report: a map for the future of education and work. http://ecosystem.edtechxeurope.com/2016-edtech-report. Accessed 04 Dec 2019.

Fahimirad, M., \& Kotamjani, S. S. (2018). A review on application of artificial intelligence in teaching and learning in educational context. International Journal of Learning and Development, 8(4), 106-118.

Ferguson, R. (2012). Learning analytics: Drivers, developments and challenges. International Journal of Technology Enhanced Learning, 4(5/6), 304-317.

Ferguson, R., \& Clow, D. (2017). Where is the evidence? A call to action for learning analytics. In Proceedings of the Seventh International Learning Analytics \& Knowledge Conference, (pp. 56-65). New York: ACM.

Freikamp, U. (2008): Kritik mit Methode? Forschungsmethoden und Gesellschaftskritik. Unter Mitarbeit von Ullrich, P.. Berlin: Dietz (Texte / Rosa-Luxemburg-Stiftung, 42). http://www.rosalux.de/cms/fileadmin/rls_uploads/pdfs/Texte-42.pdf, Accessed 27 Feb 2020.

Gartner (2012). What is big data? Gartner IT glossary—big data. https:/www.gartner.com/it-glossary/big-data/. Accessed 11 May 2018.

Gasevic, D., Dawson, S., Rogers, T., \& Gasevic, D. (2016). Learning analytics should not promote one size fits all: The effects of instructional conditions in predicting academic success. Internet and Higher Education, 28, 68-84.

Hartmann, P. M., Zaki, M., Feldmann, N., \& Neely, A. (2016). Capturing value from big data—A taxonomy of data-driven business models used by start-up firms. International Journal of Operations \& Production Management, 36(10), 1382-1406.

Hilbig, R. (2019). Internationale Geschäftsmodelle von Berufsbildungsdienstleistern- Geschäftsmodellinnovationen unter Berücksichtigung der Dynamic Capabilities. Wiesbaden: Springer Gabler Verlag.

Hilbig, R., Estiwah, B., \& Hecht, S. (2018). Berlin start-ups-the rise of data-driven business models. In ISPIM Connects Fukuoka Building on Innovation Tradition, 2-5 December, (pp. 1-19). Fukuoka.

Hilbig, R., Renz, A., \& Schildhauer, T. (2019). Data analytics: The future of innovative teaching and learning. In ISPIM Conference Proceedings, The International Society for Professional Innovation Management (ISPIM), (pp. 1-16). Florence.

Holmes, W., Bialik, M., \& Fadel, C. (2019). Artificial intelligence in education: Promises and implications for teaching and learning Boston: Center for Curriculum Redesign.

Huda, M., Jasmi, K. A., Mustari, I., Basiron, B., \& Sabani, N. (2017). Traditional wisdom on sustainable learning: An insightful view from Al-Zarnuji's Ta 'lim al-Muta 'allim. SAGE Open, 7(1), 1-8.

Ifenthaler, D., \& Yau, J. Y.-K. (2019). Higher education stakeholders' views on learning analytics policy recommendations for supporting study success. International Journal of Learning Analytics and Artificial Intelligence for Education (iJAl), 1(1), 28-42.

Istrate, A. M. (2019). The Impact of the Virtual Assistant (VA) on Language Classes. In The International Scientific Conference elearning and Software for Education, (vol. 1, pp. 296-301). "Carol I" National Defence University, Bucharest.

Jäger, S. (2015): Kritische Diskursanalyse. Eine Einführung. 7., voll- ständig überarbeitete Auflage. Münster: Unrast (Edition DISS, Bd. 3).

Jonassen, D., Davidson, M., Collins, M., Campbell, J., \& Haag, B. B. (1995). Constructivism and computer-mediated communication in distance education. American Journal of Distance Education, 9(2), 7-26.

Kalyani, D., \& Rajasekaran, K. (2018). Innovative teaching and learning. Journal of Applied and Advanced Research, 3(1), 23-25.

Keller, R. (2011). Diskursforschung: Eine Einführung für Sozialwissenschaftlerlnnen. Wiesbaden: VS Verlag.

KMK. (2017). Das Bildungswesen in der Bundesrepublik Deutschland 2015/2016 - Darstellung der Kompetenzen, Strukturen und bildungspolitischen Entwicklungen für den Informationsaustausch in Europa. https://www.kmk.org/dokumentationstatistik/informationen-zum-deutschen-bildungssystem/dossier-deutsch.html. Accessed 01 Aug 2019.

Labarthe, H., Luengo, V., \& Bouchet, F. (2018) Analyzing the relationships between learning analytics, educational data mining and Al for education. 14th International Conference on Intelligent Tutoring Systems (ITS): Workshop Learning Analytics, June 2018, Montreal, Canada, 10-19.

Li, X. (2007). Intelligent agent-supported online education. Decision Sciences Journal of Innovative Education, 5(2), 311-331.

Long, P., \& Siemens, G. (2011). Penetrating the fog: Analytics in learning and education. Educause Review, 46(5), 31-40.

Loop, J. (2016). The empowered learner. White paper. https://www.looop.co/wp-content/uploads/2015/09/The-EmpoweredLearner-White-Paper.pdf. Accessed 31 Jul 2019.

Lorenz, P., \& Saslow, K. (2019). Demystifying Al \& Al companies-What foreign policy makers need to know about the global Al industry. Stiffung Neue Verantwortung, https:/www.stiftung-nv.de/de/publikation/demystifying-ai-ai-companies-whatforeign-policy-makers-need-know-about-global-ai. Accessed 31 July 2019.

Luckin, R., Holmes, W., Griffiths, M., \& Forcier, L. B. (2016). Intelligence unleashed. An argument for Al in education. London: Pearson.

Macfadyen, L. P., Dawson, S., Pardo, A., \& Gaševic, D. (2014). Embracing big data in complex educational systems: The learning analytics imperative and the policy challenge. Research \& Practice in Assessment, 9, 17-28. 
Manyika, J., Chui, M., Brown, B., Bughin, J., Dobbs, R., Roxburgh, C., \& Byers, A. H. (2011). Big data: The next frontier for innovation, competition and productivity. McKinsey Global Institute http://www.mckinsey.com/insights/business_ technology/big_data_the_next_frontier_for_innovation. Accessed 31 July 2019.

Maseleno, A., Sabani, N., Huda, M., Ahmad, R., Jasmi, K. A., \& Basiron, B. (2018). Demystifying learning analytics in personalised learning. International Journal of Engineering \& Technology, 7(3), 1124-1129.

Mayer-Schonberger, V., \& Cukier, K. (2014). Learning from big data: The future of education. New York: Houghton Mifflin Harcourt.

Mayring, P. (2010). Qualitative Inhaltsanalyse. Grundlagen und Techniken. 11. aktualisierte und überarbeitete Version. Weinheim und Basel: Beltz Verlag.

Newland, B., Martin, L., \& Ringan, N. (2015). Learning analytics, in UK HE 2015. A HeLF Survey Report, https://drive.google. com/file/\%20d/0Bz7E74T5Am22UEM1c0FxRjVpMzA/view. Accessed 31 July 2019.

Perez, S., Massey-Allard, J., Butler, D., Ives, J., Bonn, D., Yee, N., \& Roll, I. (2017). Identifying productive inquiry in virtual labs using sequence mining. In International Conference on Artificial Intelligence in Education, (pp. 287-298). Cham: Springer.

Picciano, A. G. (2014). Big data and learning analytics in blended learning environments: Benefits and concerns. International Journal of Artificial Intelligence and Interactive Multimedia, 2(7), 35-43.

Popenici, S. A. D., \& Kerr, S. (2017). Exploring the impact of artificial intelligence on teaching and learning in higher education. Research and Practice in Technology Enhanced Learning, 12(22), 1-13.

Prifti, P., Knigge, M., Löffler, A., Hecht, S., \& Krcmar, H. (2017). Emerging business models in education provisioning: A case study on providing learning support as education-as-a-service. International Journal of Engineering Pedagogy, 7(3), 92-108.

Prinsloo, P., Slade, S., \& Galpin, F. (2012). Learning analytics: Challenges, paradoxes and opportunities for mega open distance learning institutions. In Conference paper at the $2^{\text {nd }}$ international conference on learning analytics and knowledge. Vancouver.

Renz, A., Krishnaraja, S., \& Gronau, E. (2020). Demystification of artificial intelligence in education-how much Al is really in the educational technology? International Journal of Learning Analytics and Artificial Intelligence for Education, 2(1), 4-30.

Rittelmeyer, C. (2017). Digitale Bildung - ein Widerspruch: Erziehungswissenschaftliche Analysen der schulbezogenen Debatten (Pädagogik: Perspektiven und Theorien, Band 29). Oberhausen: Athena Verlag.

Ritter, T., \& Lettl, C. (2017). The wider implications of business-model research. Long Range Planning, 51(1), 1-8.

Rothe, H., Täuscher, K., \& Basole, R. C. (2018). Competition between platform ecosystems: A longitudinal study of MOOC platforms. In Twenty-Sixth European Conference on Information Systems (ECIS2018), (pp. 1-18). Portsmouth.

Russell, S. J., \& Norvig, P. (2010). Artificial intelligence: A modern approach, (3rd ed., ). Upper Saddle River: Prentice-Hall.

Schüritz, R., Seebacher, S., \& Dorner, R. (2017). Capturing value from data: revenue models for data-driven services. In Proceedings of the 50th Hawaii International Conference on System Sciences, 4-7 January, (pp. 5348-5357). Hawaii.

Sclater, N., Peasgood, A., \& Mullan, J. (2016). Learning analytics in higher education: A review of UK and international practice. Bristol: JISC.

Self, J. (2016). The birth of IJAIED. International Journal of Artificial Intelligence in Education, 26(4), 4-12.

Seyda, S., Meinhard, D. B., \& Placke, B. (2018). Weiterbildung 4.0: Digitalisierung als Treiber und Innovator betrieblicher Weiterbildung. https://www.iwkoeln.de/studien/iw-trends/beitrag/susanne-seyda-david-b-meinhard-beate-plackedigitalisierung-als-treiber-und-innovator-betrieblicher-weiterbildung-385131.html. Accessed 25 Mar 2019.

Slade, S., \& Prinsloo, P. (2013). Learning analytics: Ethical issues and dilemmas. American Behavioral Scientist, 57(10), 1510-1529.

Startup Genome. (2018). Global Startup Ecosystem Report 2018-Succeeding in the New Era of Technology. https:// startupgenome.com/all-report-thank-you/ffile=2018. Accessed 25 Mar 2019.

Startup Genome. (2019). Global Startup Ecosystem Report 2019-Succeeding in the New Era of Technology. https:// startupgenome.com/reports/global-startup-ecosystem-report-2019. Accessed 22 Nov 2019.

Teece, D. J. (2010). Business models, business strategy and innovation. Long Range Planning, 43(2-3), 172-194.

Trifilova, A., Bessant, J., \& Alexander, A. (2016). Q\&A. How can you teach innovation and entrepreneurship? Technology Innovation Management Review, 6(10), 45-50.

Tsai, Y.S., \& Gasevic, D. (2017). Learning analytics in higher education—Challenges and policies: A review of eight learning analytics policies. The Seventh International Learning Analytics \& Knowledge Conference, Canada, Vancouver.

Viberg, O., Hatakka, M., Bälter, O., \& Mavroudi, A. (2018). The current landscape of learning analytics in higher education. Computers in Human Behavior, 89, 98-110.

Weller, M. (2018). Twenty years of EdTech. Educause Review Online, 53(4), 34-48.

Williamson, B. (2018). The hidden architecture of higher education: building a big data infrastructure for "smarter university". International Journal of Educational Technology in Higher Education, 15(12), 1-26.

Yin, R. K. (2014). Case study research. Design and methods, (5th ed., ). Thousand Oaks: Sage.

Zawacki-Richter, O., Marín, V. I., Bond, M., \& Gouverneur, F. (2019). Systematic review of research on artificial intelligence applications in higher education-where are the educators? International Journal of Educational Technology in Higher Education, 16(39), 1-27.

Zott, C., Amit, R., \& Massa, L. (2011). The business model: Recent developments and future research. Journal of Management, 37(4), 1019-1042.

\section{Publisher's Note}

Springer Nature remains neutral with regard to jurisdictional claims in published maps and institutional affiliations. 